\title{
The Relevance of Family History Taking in the Detection and Management of Birt-Hogg-Dubé Syndrome
}

\author{
Elena Torricelli ${ }^{a}$ Mariaelena Occhipinti ${ }^{a} \quad$ Edoardo Cavigli ${ }^{b} \quad$ Giorgia Tancredi $^{c}$ \\ Elisabetta Rosi ${ }^{a}$ Cesare Rossi $^{d}$ Michela Bonaguro $^{d}$ Luisa Candita ${ }^{\mathrm{e}}$ \\ Laura Papi $^{\mathrm{e}}$ Luca Novelli $^{\mathrm{f}}$ Michela Bezzi ${ }^{\mathrm{g}}$ Elena Bargaglia ${ }^{\mathrm{a}}$ Luca Voltolinic \\ Massimo Pistolesi ${ }^{a}$
}

a Section of Respiratory Medicine, Department of Clinical and Experimental Medicine, University of Florence, Florence, Italy; ${ }^{b}$ Section of Radiodiagnostics, Department of Services, Careggi University Hospital, Florence, Italy; 'Section of Thoracic Surgery, Department of Surgery, University of Florence, Florence, Italy; ${ }^{\mathrm{d}}$ Section of Medical Genetics, Sant'Orsola-Malpighi Hospital, Bologna, Italy; e Section of Medical Genetics, Department of Experimental and Clinical Biomedical Sciences, University of Florence, Florence, Italy; fSection of Histopathology and Molecular Pathology, University of Florence, Florence, Italy; ${ }^{9}$ Division of Interventional Pulmonology, Careggi University Hospital, Florence, Italy

\section{Keywords}

Pneumothorax · Birt-Hogg-Dubé syndrome ·

Pneumothorax · FLCN protein · Rare diseases · Cysts ·

Prevalence $\cdot$ Computed tomography $\cdot$ Radiography

\begin{abstract}
Background: Birt-Hogg-Dubé syndrome (BHDS) is a rare autosomal-dominant inherited disorder characterized by inactivation of the gene Folliculin ( FLCN), pulmonary cysts with recurrent spontaneous pneumothorax, dermatological lesions, and an increased risk of developing renal malignancies. Objectives: We aimed to investigate the real prevalence of BHDS and its prevalence among patients with a familial history of pneumothorax. Methods: From July 2014 to December 2016, we consecutively studied all patients with
\end{abstract}

() 2019 S. Karger AG, Basel

E-Mail karger@karger.com www.karger.com/res spontaneous pneumothorax and a positive family history for the same condition referring to our Institution. The suspicious cases underwent genetic analysis of the BHDS-causative gene FLCN. FLCN-positive cases were further evaluated with routine blood tests, chest radiography, chest $C T$, abdominal MRI, and dermatological evaluation. Results: Among 114 patients admitted with spontaneous pneumothorax, 7 patients had a family history of pneumothorax, and $6 / 7$ (85.7\%) patients had positive genetic test for FLCN as well as $7 / 13$ family members. Pulmonary cysts were found in all patients with a FLCN-positive genetic test. Most patients $(10 / 13,76.9 \%)$ had tiny pulmonary cysts less than $1 \mathrm{~cm}$ in diameter. The vast majority of cysts were intraparenchymal $(12 / 13,92.3 \%)$ and located in lower lobes. Dermatological lesions were found in $7 / 13$ (54\%) patients, renal cysts in 4/13 (31\%) patients, and renal cancer in $1(1 / 13,7.7 \%)$ patient. 
Conclusions: Although BHDS is considered a rare disease, BHDS underlies spontaneous pneumothorax more often than usually believed, especially whenever a family history of pneumothorax is present. Diagnosis of BHDS is essential to start monitoring patients for the risk of developing renal malignancies.

(c) 2019 S. Karger AG, Basel

\section{Introduction}

Birt-Hogg-Dubé syndrome (BHDS) is an autosomaldominant inherited disorder described in 1977 by three Canadian researchers who gave the name to the syndrome. BHDS is characterized by dermatological lesions such as fibrofolliculomas and trichodiscomas, thinwalled bilateral pulmonary cysts, increased risk of malignant renal neoplasms, and spontaneous pneumothorax [1]. With respect to the general population, subjects with BHDS have sevenfold increased risk of developing renal malignancies and fiftyfold increased risk of spontaneous pneumothorax $[2,3]$.

BHDS-associated gene locus was localized in chromosome $17 \mathrm{p} 11.2$, and it was subsequently demonstrated that a novel gene, called Folliculin (FLCN), was inactivated in individuals with BHDS. Folliculin is a protein that has a putative tumor suppressor function. Germline mutations in the FLCN gene were first identified in BHDS in 2002 [4].

The prognosis of BHDS is mainly related to the development of renal cancer, being the dermatological and pulmonary localizations generally associated with benign prognosis.

The incidence of this syndrome is still unknown, with approximately 616 families diagnosed around the world (www.bhdsyndrome.org). Data on the real distribution of the disease in Italy, where only about 15 families with BHDS have been reported (www.bhdsyndrome.org), are lacking. Clinical, genetic, and radiological features of Italian BHDS patients have been published in a limited number of case reports in which data mainly related to single patients are described. Recently Tomasetti et al. [5] reported in detail the pulmonary features of 10 BHDS patients from 3 unrelated families identified from 2005 to 2010.

We aimed at studying the BHDS incidence among patients referred to our hospital for spontaneous pneumothorax to ascertain whether the real prevalence of the syndrome could be underestimated. Furthermore, we characterized the genetic mutations as well as the findings on chest radiography, chest computed tomography (CT), and abdomen magnetic resonance imaging (MRI) of subjects with identified FLCN mutation.

\section{Materials and Methods}

From July 2014 to December 2016, a clinical suspicion of BHDS was raised in all patients who presented at Careggi University Hospital with spontaneous pneumothorax and had a family history of pneumothorax in any first-degree relative. This cohort study received approval by the local ethic committee, and all subjects have given their written informed consent.

The identified cases underwent genetic analysis of the BHDScausative gene FLCN according to methods described in the literature $[3,4]$. Genomic DNA was extracted from peripheral blood leukocytes and subjected to polymerase chain reaction and Sanger cycle-sequencing. The sequencing reactions were run on ABI3730 DNA Analyzer and the resulting chromatograms read and annotated manually $[3,4]$. The first-degree relatives of patients with positive genetic results (probands) were asked to participate in the study. Probands as well as their family members provided written informed consent before undergoing genetic analysis.

Probands and their relatives with positive genetic analysis underwent accurate evaluation of personal and familial clinical history, routine blood tests (including renal and liver tests), chest radiography, chest CT, abdomen MRI, and dermatological evaluation.

Chest radiographs were evaluated for the presence of pneumothorax. CT scans were evaluated for the presence of lung cysts. Lung cysts were described in relation to number, maximum diameter $(<1,1-2,2-5,>5 \mathrm{~cm})$, shape (round, oval), margins (thin, thick), location (paramediastinal, perifissural, intraparenchymal), unilaterality or bilaterality, lobar distribution, clusters aggregation.

The presence of renal lesions was evaluated by abdomen MRI. Fibrofolliculomas and trichodiscomas were searched by dermatological evaluation.

\section{Results}

Among 463 consecutive patients admitted in 18 months to our hospital with a diagnosis of pneumothorax, traumatic $(217,47 \%)$ and spontaneous $(114,25 \%)$ pneumothorax were the most common clinical conditions. Pneumothorax was iatrogenic in 36 patients $(8 \%)$, due to lung cancer in 33 patients (7\%) and to lung infections in 33 patients (7\%). Less common causes were emphysema, interstitial lung disease, catamenial, and lymphangioleiomyomatosis (LAM).

A family history of pneumothorax was identified in 7/114 (6\%) of patients with a spontaneous pneumothorax. FLCN mutations were positive in $6 / 7$ (86\%) pa- 
Fig. 1. CONSORT diagram of the population studied. Patients with positive results for Folliculin gene (FLCN) mutations at genetic analysis were the 6 probands and their 7 first-degree relatives. PNX, pneumothorax; ILD, interstitial lung disease; LAM, lymphangioleiomyomatosis.

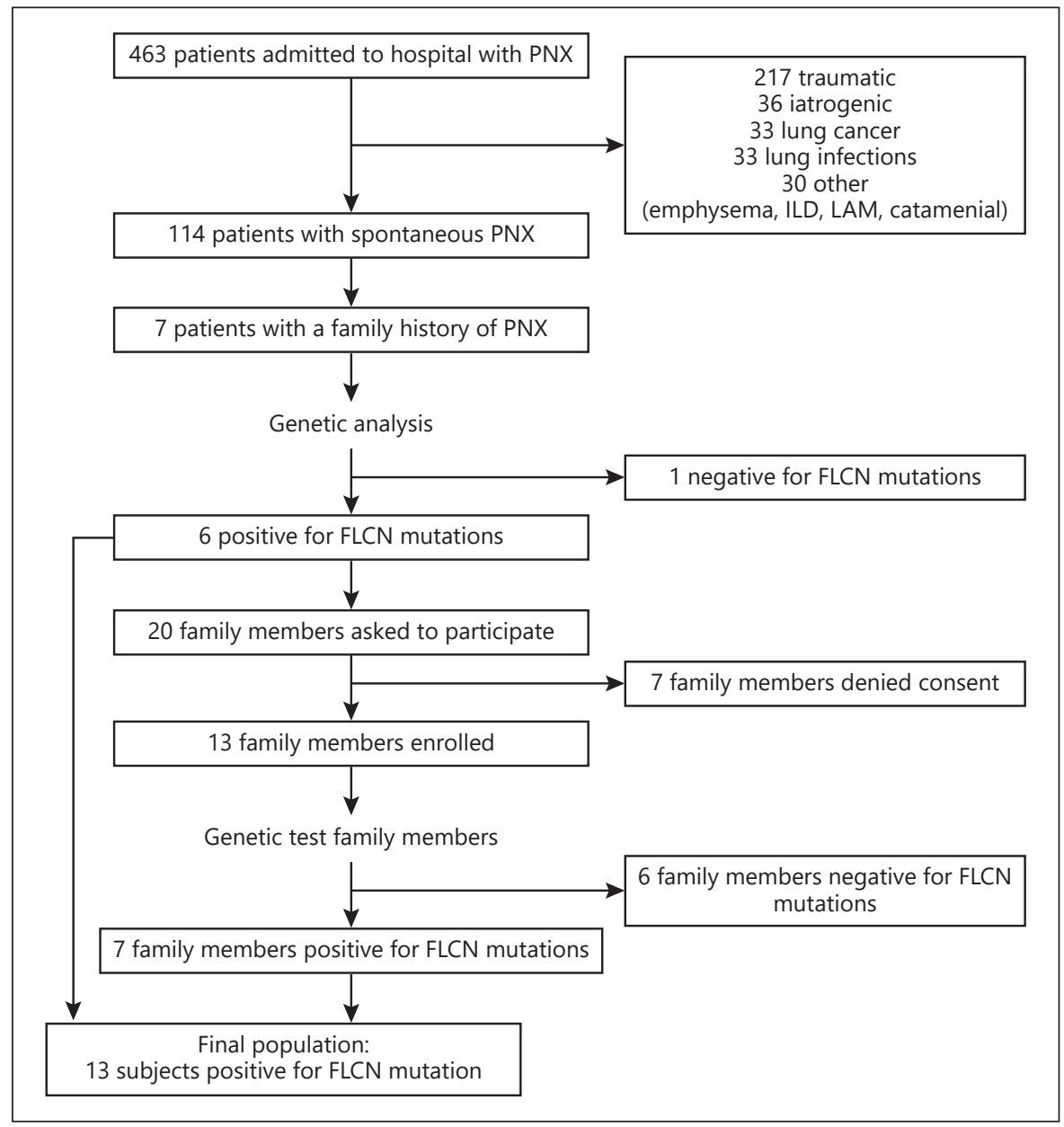

Surgical lung biopsy specimens were available in 3 patients $(2 \mathrm{~A}, 3 \mathrm{~A}, 4 \mathrm{~A})$. Histological specimens showed pulmonary cysts characterized by cystic dilatation of alveolar spaces ranging from microscopic foci to a few millimeters in diameter. The pulmonary cysts were lined by a thin layer of cuboidal epithelium, without fibrous or smooth muscle tissue, and were surrounded by normal parenchyma (Fig. 2).

The genetic analysis revealed five distinct mutations in the FLCN gene: a non-sense c.1429C>T, p.Arg477* mutation (family 1), a 1 base insertion c.1277-1278 insC leading to frameshift (family 4); 2-bp deletion in exon 14 c.1596-1599 delCA (reported as a single ClinVar entry, RCV000219888.1), the donor splice site mutations in intron 11 (recurrent in families 2 and 5), and in intron 12 (family 4) [6-8]. Overall, the sequence changes were preferentially located in exon/intron 11-12. In addition to the recurrent splice site mutation, three additional mutations were found in this region, as listed in Table 1. 
Fig. 2. Hematoxylin-eosin staining of lung specimens of patient $2 \mathrm{~A}$ who underwent surgical lung biopsy. a The low-power magnification section shows a mild mononuclear inflammatory infiltrate along the interlobular septa and normal lung parenchyma surrounding the septa. $\mathbf{b}$ The highpower magnification section shows the wall of a subpleural cyst consisting of a single layer of cuboid mesothelial cells.
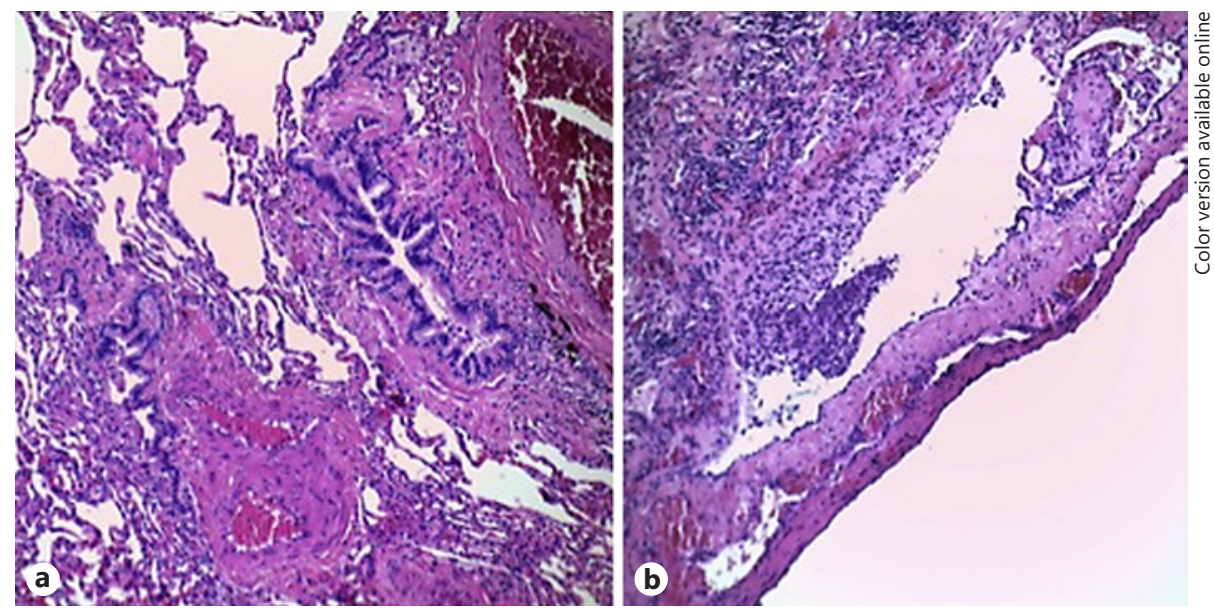

Table 1. Clinical, radiological, and genetic characteristics of the 13 subjects with positive genetic tests for the FLNC gene

\begin{tabular}{|c|c|c|c|c|c|c|c|c|c|c|c|c|}
\hline $\begin{array}{l}\text { Family } \\
\text { ID }\end{array}$ & $\begin{array}{l}\text { Subject } \\
\text { ID }\end{array}$ & Age & Sex & BMI & Mutation & Effect & $\begin{array}{l}\text { Exon/ } \\
\text { intron }\end{array}$ & PNX & $\begin{array}{l}\text { Lung } \\
\text { cysts }\end{array}$ & $\begin{array}{l}\text { Renal } \\
\text { cysts }\end{array}$ & $\begin{array}{l}\text { Renal } \\
\text { cancer }\end{array}$ & Fibrofolliculomas \\
\hline 1 & $1 \mathrm{~A}$ & 69 & M & 28 & c.1429 C>T, p.Arg477* & NS & $\mathrm{e} 12$ & 1 & 1 & 0 & 0 & 1 \\
\hline \multirow[t]{3}{*}{2} & $2 \mathrm{~A}$ & 43 & M & 23.3 & c. $1300+2 \mathrm{~T}>\mathrm{C}$ & $S D S$ & i11 & 1 & 1 & 1 & 0 & 1 \\
\hline & $2 \mathrm{~B}$ & 47 & M & 28.4 & c. $1300+2 \mathrm{~T}>\mathrm{C}$ & SDS & i11 & 1 & 1 & 1 & 0 & 1 \\
\hline & $2 \mathrm{C}$ & 73 & $\mathrm{~F}$ & 27.3 & c. $1300+2 \mathrm{~T}>\mathrm{C}$ & SDS & i11 & 1 & 1 & 1 & 0 & 0 \\
\hline 3 & $3 \mathrm{~B}$ & 46 & $\mathrm{~F}$ & 26.3 & c. $1422+1 \mathrm{G}>\mathrm{T}$ & $S D S$ & $\mathrm{i} 12$ & 1 & 1 & 0 & 0 & 0 \\
\hline \multirow[t]{3}{*}{4} & $4 \mathrm{~A}$ & 38 & M & 25 & c.1277-1278insC & FS & i11 & 1 & 1 & 0 & 0 & 1 \\
\hline & $4 \mathrm{~B}$ & 40 & M & 24.2 & c.1277-1278insC & FS & e11 & 0 & 1 & 0 & 0 & 0 \\
\hline & $4 \mathrm{C}$ & 68 & M & 25 & c.1277-1278insC & $F S$ & e11 & 0 & 1 & 0 & 1 & 1 \\
\hline 5 & $5 \mathrm{~A}$ & 37 & M & 22 & c. $1300+2 \mathrm{~T}>\mathrm{C}$ & SDS & i11 & 1 & 1 & 0 & 0 & 1 \\
\hline
\end{tabular}

All the reported mutations were found in heterozygosity. Probands are identified with " $A$ " in subject ID, whereas " $B$ " and " $C$ " indicate their relatives. NS, non-sense; PNX, pneumothorax; SDS, splicing donor site; FS, frameshift.

Chest radiography showed the presence of pneumothorax in the 6 probands as well as hyperlucent areas along the paramediastinal regions in $4 / 13$ (31\%) subjects. In these 4 cases, the radiographic hyperlucencies corresponded to cysts larger than $5 \mathrm{~cm}$ in paramediastinal regions on CT scan.

Chest CT scan showed bilateral lung cysts in all 13 cases $(100 \%)$, with a clear predominance on the lower lobes (12/13 cases). Most cysts were intraparenchymal $(12 / 13)$ and paramediastinal (11/13) (Fig. 3a). Only 3 patients had less than 10 lung cysts (Fig. 4), while the remaining patients had cysts diffusely distributed (more than 20). The majority of patients had small cysts, with a maximum axial diameter less than $1 \mathrm{~cm}$. Only 4 patients had cysts larger than $5 \mathrm{~cm}$. Cysts were aggregated in clusters in 4 out of the 6 subjects with numerous cysts (Fig. 3b). Cysts had oval-rounded shape in 11/13 patients and were perfectly round in $2 / 13$. Cyst margins were thin in most patients (9/13). Detailed imaging characteristics of lung cysts are shown in Table 2. No differences in lung cyst characteristics were found between probands and their relatives and between subjects with a history of pneumothorax and those without. 

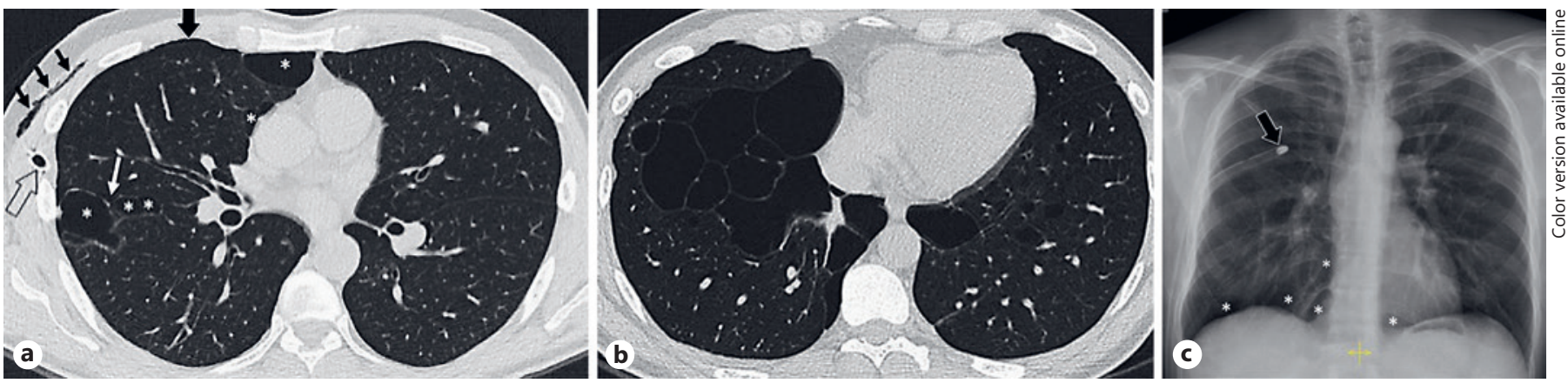

Fig. 3. Chest CT of patient $2 \mathrm{~A}$ shows the presence of air in the right pleural space, with the visceral pleural line detached from the parietal layer (thick black arrow) and air surrounding the cysts along the right main fissure (white arrow), consistent with pneumotho$\operatorname{rax}(\mathbf{a})$. Bilateral thin-walled cysts can be seen in the lung parenchyma, distributed mainly in the periphery along the pleural surface, both in the paramediastinal area (asterisks) and in the supradiaphragmatic area (b). Note the air bubbles (thin black arrows)

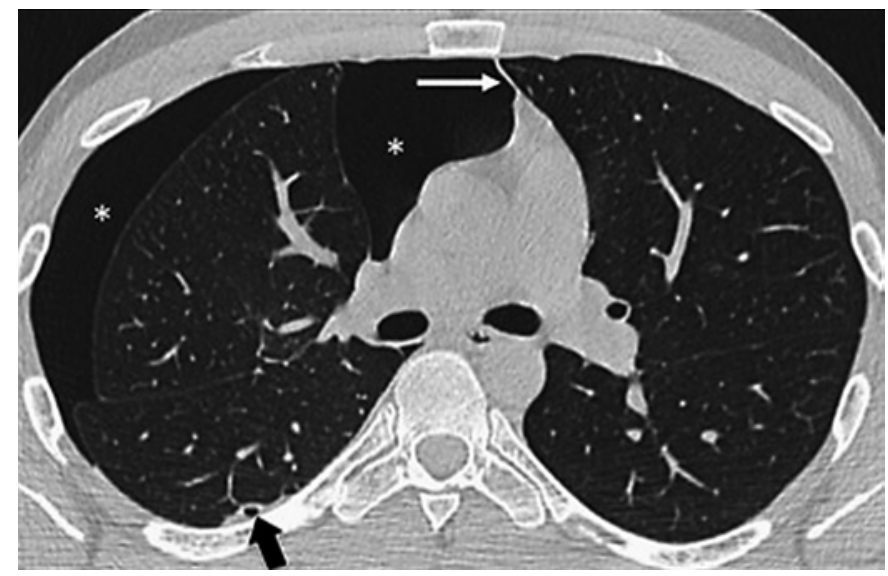

Fig. 4. Chest $\mathrm{CT}$ of patient $3 \mathrm{~A}$ presenting with recurrent spontaneous pneumothorax and a family history of spontaneous pneumothorax (his mother). CT scan shows the presence of abundant air (asterisks) in the right pleural space and a slight deviation of the mediastinum with the anterior conjunction line (white arrow) towards the left side, as of tension pneumothorax. Note the 5-mm round parenchymal cyst (black arrow) in the apical segment of the right lower lobe located along the posterior pleural surface and surrounded by atelectasis of adjacent lung. Other three little round cysts were present in the right middle lobe as well as in the left lung.

On MRI of the abdomen, 4/13 subjects presented mono- or bilateral renal cysts at presentation (families 2 and 5), and patient $4 \mathrm{~B}$ had a "horseshoe" kidney. Only 1 patient had a previous history of renal clear cell carcinoma (at the age of 46), treated with surgery.

Dermatological lesions were observed in 7 subjects. Typical face and/or neck fibrofolliculomas were observed

Family History in Birt-Hogg-Dubé Syndrome dissecting the muscles of the right chest wall, consistent with subcutaneous emphysema. A chest tube (open arrow) was inserted along the right mid-axillary line to treat the pneumothorax. Follow-up chest radiography (c) shows the location of the tip (arrow) of the chest tube in the upper third of the right hemithorax. Hyperlucent areas can be seen in the lower third of the right lung, in both the paramediastinal and the supradiaphragmatic regions (asterisks), consistent with the large lung cysts seen on CT.

in 5 probands (5/6) (Fig. 5). Histological examination was not obtained. Although no skin lesions were found in 5 subjects with a positive FLCN gene mutation, at least 1 member of each family showed typical cutaneous lesions. Skin involvement was present in all patients younger than 40 years and in $4 / 5$ subjects older than 40 years.

The main comorbidities were arterial hypertension (4/13), breast cancer (2/13), myelodysplastic syndrome $(1 / 13)$, and asthma (1/13).

\section{Discussion}

We found a BHDS prevalence slightly exceeding $6 \%$ in 114 consecutive patients referred to our Institution for spontaneous pneumothorax. The prevalence was as high as $86 \%(6 / 7)$ among patients with a family history of pneumothorax. All probands and their relatives had lung cysts at CT scan, 7 subjects had typical dermatological lesions, and 1 subject had renal cancer. Five distinct mutations in FLCN gene, preferentially located in exon/intron 11-12, were identified.

BHDS prevalence among patients with a family history of pneumothorax is at present unknown. In agreement with our data, a $4.5-10 \%$ prevalence among patients with spontaneous pneumothorax has been estimated [9].

Spontaneous pneumothorax typically occurs in young, tall, and thin subjects [10-12]. In this study, BHDS patients with pneumothorax were unusually older (mean age 42) and had a normal weight (mean BMI 24.7). 
Table 2. Characteristics of lung cysts at chest CT scan in 13 subjects with positive genetic tests for the FLNC gene

\begin{tabular}{|c|c|c|}
\hline & Cases, $n$ & $\%$ \\
\hline \multicolumn{3}{|l|}{ Lung predominance } \\
\hline Right & $7 / 13$ & 53.8 \\
\hline Left & $4 / 13$ & 30.8 \\
\hline Balanced & $2 / 13$ & 15.4 \\
\hline \multicolumn{3}{|l|}{ Lobar distribution } \\
\hline RUL & $9 / 13$ & 69.2 \\
\hline RML & $10 / 13$ & 76.9 \\
\hline RLL & $12 / 13$ & 92.3 \\
\hline LUL & $8 / 13$ & 61.5 \\
\hline LLL & $11 / 13$ & 84.6 \\
\hline Bilaterality & $13 / 13$ & 100 \\
\hline \multicolumn{3}{|l|}{ Location } \\
\hline Intraparenchymal & $12 / 13$ & 92.3 \\
\hline Paramediastinal & $11 / 13$ & 84.6 \\
\hline Perifissural & $9 / 13$ & 69.2 \\
\hline \multicolumn{3}{|l|}{ Diameter } \\
\hline$<1 \mathrm{~cm}$ & $10 / 13$ & 76.9 \\
\hline $1-2 \mathrm{~cm}$ & $9 / 13$ & 69.2 \\
\hline $2-5 \mathrm{~cm}$ & $5 / 13$ & 38.5 \\
\hline$>5 \mathrm{~cm}$ & $4 / 13$ & 30.8 \\
\hline \multicolumn{3}{|l|}{ Numerosity } \\
\hline$<10$ & $3 / 13$ & 23.1 \\
\hline $10-20$ & $2 / 13$ & 15.4 \\
\hline$>20$ & $6 / 13$ & 46.1 \\
\hline Clusters & $4 / 13$ & 30.8 \\
\hline \multicolumn{3}{|l|}{ Shape } \\
\hline Only round & $2 / 13$ & 15.4 \\
\hline Oval-rounded & $11 / 13$ & 84.6 \\
\hline \multicolumn{3}{|l|}{ Margins } \\
\hline Thin & $9 / 13$ & 69.2 \\
\hline Both thin and thick & $4 / 13$ & 30.8 \\
\hline
\end{tabular}

The prevalence of spontaneous pneumothorax in BHDS differs in relation to the cohorts reported (dermatological, renal, or pulmonary) ranging from 23 to $38 \%$ in dermatological/renal cohorts $[3,13,14]$ and from 42 to $76 \%$ in pulmonary cohorts $[15,16]$. Pneumothorax recurs in $75-80 \%$ of BHDS patients $[13,15,16]$ with an average number of 3.6 lifetime episodes [15].

Along with pneumothorax, all probands and their relatives in our study had lung cysts at CT scan. The association of spontaneous pneumothorax with lung cysts is a clinical presentation common to several pathological conditions involving other organs besides the lung. Marfan syndrome [7, 17], Ehlers-Danlos syndrome [18, 19], pulmonary Langerhans cell histiocytosis [20, 21], LAM $[22,23]$, cystic fibrosis $[24,25]$, tuberous sclerosis, and BHDS are the main differential diagnoses to consider in this clinical presentation setting. Differential diagnosis of the disorder underlying spontaneous pneumothorax is crucial in patient management because associated pathological conditions (e.g., renal cancer in BHDS) need specific follow-up. In the above-mentioned conditions pneumothorax recurrence is common with the highest rate (70\%) among patients with LAM [23]. LAM is the cystic disease to be differentiated from BHDS in females of childbearing age. LAM and BHDS share some similar features in their clinical expression, but differ markedly in many other aspects [26]. Tobino et al. [27] found that pulmonary cysts in BHDS were less in number and extent, less circular in shape, but bigger in size, and more often located in lower-medial lung regions with respect to those observed in LAM. Marfan syndrome, Ehlers-Danlos syndrome, and cystic fibrosis are usually diagnosed at birth or during the first years of life; therefore, the differential is made easy by history and associated clinical findings $[25,28]$. Patients with tuberous sclerosis and BHDS share common features. Both may have lung cysts, renal tumors, and dermatological lesions. In tuberous sclerosis besides the typical cysts of LAM, large angiomyolipomas may be found on abdominal ultrasounds [29]. The rate of renal cancer in tuberous sclerosis is, however, similar to that of the general population, occurring at younger age though $[29,30]$.

The patient who developed renal cancer in our cohort was 46 years old. Patients with BHDS are more prone to develop renal carcinomas than the general population, with $30 \%$ of patients developing solitary or multifocal lesions at a median age of 48 years [14, 31]. Most renal tumors are bilateral, multifocal, and slow-growing. Histological subtypes include chromophobe oncocytomas (50\%), chromophobe carcinomas (34\%), clear cell carcinomas (9\%), oncocytomas (5\%), and papillary renal cell cancers (2\%) [32-34]. Although CT is much more sensitive than ultrasound (100 vs. $58 \%$, respectively) in detecting small renal lesions $(1.5-2 \mathrm{~cm})$, the lifetime radiation dose would be unacceptably high [35]. Therefore, renal MRI is the best approach to screen for renal masses in BHDS [36]. However, guidelines on the frequency of follow-up have not been issued. Based on the prevalence of kidney cancer in our cohort, we screen our BHDS patients older than 20 years by abdomen MRI biannually. Benign renal cysts have also been documented in patients with BHDS, but the exact prevalence in comparison to the general population is currently unknown $[37,38]$.

In our cohort, 7 patients ( 5 probands and 2 relatives) had typical fibrofolliculomas, i.e. hamartomas of the hair 


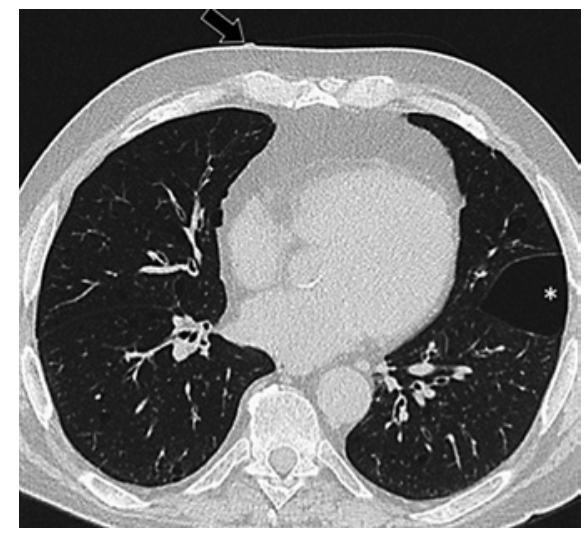

Fig. 5. Chest CT of patient $1 \mathrm{~A}$ shows an irregular profile of the skin (arrow) along the anterior chest wall, corresponding to a fibrofolliculoma. Attention to skin irregularities should be paid in patients with lung cysts. Many little cysts widely scattered in the entire lung parenchyma can be seen in this patient, together with a typical elongated lung cyst (asterisk) in the left lower lobe along the left fissure.

follicles, previously undiagnosed. Fibrofolliculomas, tumors of the hair disk (trichodiscomas), and skin tags (acrochordons) are the more commonly reported cutaneous changes in BHDS. Fibrofolliculomas are the most characteristic finding usually appearing in the third to fourth decades of life [32]. Fibrofolliculomas typically appear as multiple, whitish, smooth, dome-shaped papules, 2- to 4-mm in diameter, located over the skin of the head, neck, face, and upper trunk $[38,39]$. The skin manifestations of BHDS are benign and may go unnoticed. Although dermatologists are the specialists most often involved in the diagnosis of BHDS $[38,39]$, in our population spontaneous pneumothorax was the most common finding at presentation.

Once dermatologists, thoracic surgeons, or chest physicians have raised the suspicion of BHDS, a family history of similar spontaneous pneumothorax should be investigated and genetic analysis is strongly recommended. Molecular diagnosis could give the chance to identify, among relatives, other asymptomatic carriers of FLCN mutations, who should perform an adequate follow-up, as an early diagnosis of renal tumors is a fundamental tool of secondary prevention. Familial spontaneous pneumothorax is genetically heterogeneous and various patterns of inheritance have been reported. Although most cases of familial spontaneous pneumothorax are inherited in an autosomal dominant pattern with incomplete penetrance [39], X-linked recessive [6] as well as autosomal recessive cases have also been reported [40]. The five dis- tinct mutations in FLCN found in our population have already been described in the literature $[3,13,14,40,41]$. In our study, there was no association between BHDS mutation status, such as exonic versus intronic mutations, and skin lesions or lung cysts. So far, no clear evidence of genotype-phenotype correlations has been observed in BHDS [13]. The phenotype appears to be highly variable within and between families, and a few instances of non-penetrance have been reported. Probably, many other multiple genetic factors as well as environmental factors lie behind the different clinical features $[3,13]$. The only clear correlation between genotype and phenotype is a specific cytosine duplication in exon 11 (c.1285dupC), carrying a higher risk of developing renal cancer [3]. This duplication was found in the only patient who developed renal cancer (father of one proband) in our cohort.

In conclusion, this study indicates that the diagnosis of this rare disease is very common in those patients in whom spontaneous pneumothorax and a family history of pneumothorax coexist. This clinical association should then be actively searched to guide management and follow-up of BHDS patients and to improve their prognosis and the prognosis of their relatives. Chest physicians and thoracic surgeons should consider a possible increase in the prevalence of BHDS conditioned by a more active search of the family history of patients with spontaneous pneumothorax.

\section{Statement of Ethics}

Subjects have given their written informed consent. The study protocol has been approved by the research institute's committee on human research.

\section{Disclosure Statement}

The authors have no conflicts of interest to declare.

\section{Author Contributions}

Study concepts/study design or data acquisition or data analysis/interpretation, all authors; manuscript drafting or manuscript revision for important intellectual content, E.T., M.O., C.R., L.C., L.N., L.V., M.P.; approval of final version of submitted manuscript, all authors; agrees to ensure any questions related to the work are appropriately resolved, all authors; literature research, E.T., M.O., C.R., M.B., L.C., L.P.; and manuscript editing, all authors. L.V. and M.P. are the guarantors of the paper. 


\section{References}

1 Birt AR, Hogg GR, Dubé WJ. Hereditary multiple fibrofolliculomas with trichodiscomas and acrochordons. Arch Dermatol. 1977 Dec; 113(12):1674-7.

2 Zbar B, Alvord WG, Glenn G, Turner M, Pavlovich CP, Schmidt L, et al. Risk of renal and colonic neoplasms and spontaneous pneumothorax in the Birt-Hogg-Dubé syndrome. Cancer Epidemiol Biomarkers Prev. 2002 Apr;11(4):393-400.

3 Schmidt LS, Nickerson ML, Warren MB, Glenn GM, Toro JR, Merino MJ, et al. Germline BHD-mutation spectrum and phenotype analysis of a large cohort of families with BirtHogg-Dubé syndrome. Am J Hum Genet. 2005 Jun;76(6):1023-33.

4 Nickerson ML, Warren MB, Toro JR, Matrosova V, Glenn G, Turner ML, et al. Mutations in a novel gene lead to kidney tumors, lung wall defects, and benign tumors of the hair follicle in patients with the Birt-HoggDubé syndrome. Cancer Cell. 2002 Aug;2(2): 157-64.

5 Tomassetti S, Carloni A, Chilosi M, Maffè A, Ungari S, Sverzellati N, et al. Pulmonary features of Birt-Hogg-Dubé syndrome: cystic lesions and pulmonary histiocytoma. Respir Med. 2011 May;105(5):768-74.

6 Abolnik IZ, Lossos IS, Zlotogora J, Brauer R. On the inheritance of primary spontaneous pneumothorax. Am J Med Genet. 1991 Aug; 40(2):155-8.

7 Chiu HT, Garcia CK. Familial spontaneous pneumothorax. Curr Opin Pulm Med. 2006 Jul;12(4):268-72.

8 Noppen M. Spontaneous pneumothorax: epidemiology, pathophysiology and cause. Eur Respir Rev. 2010 Sep;19(117):217-9.

9 Johannesma PC, Reinhard R, Kon Y, Sriram JD, Smit HJ, van Moorselaar RJ, et al.; Amsterdam BHD working group. Prevalence of Birt-Hogg-Dubé syndrome in patients with apparently primary spontaneous pneumothorax. Eur Respir J. 2015 Apr;45(4):1191-4.

10 Withers JN, Fishback ME, Kiehl PV, Hannon JL. Spontaneous pneumothorax. Suggested etiology and comparison of treatment methods. Am J Surg. 1964 Dec;108(6):772-6.

11 Primrose WR. Spontaneous pneumothorax: a retrospective review of aetiology, pathogenesis and management. Scott Med J. 1984 Jan; 29(1):15-20.

12 Melton LJ 3rd, Hepper NG, Offord KP. Influence of height on the risk of spontaneous pneumothorax. Mayo Clin Proc. 1981 Nov; 56(11):678-82.

13 Toro JR, Pautler SE, Stewart L, Glenn GM, Weinreich $\mathrm{M}$, Toure $\mathrm{O}$, et al. Lung cysts, spontaneous pneumothorax, and genetic associations in 89 families with Birt-HoggDubé syndrome. Am J Respir Crit Care Med. 2007 May;175(10):1044-53.

14 Toro JR, Wei MH, Glenn GM, Weinreich M, Toure O, Vocke C, et al. BHD mutations, clinical and molecular genetic investigations of
Birt-Hogg-Dubé syndrome: a new series of 50 families and a review of published reports. I Med Genet. 2008 Jun;45(6):321-31.

15 Gupta N, Kopras EJ, Henske EP, James LE, El-Chemaly S, Veeraraghavan S, et al. Spontaneous pneumothoraces in patients with BirtHogg-Dubé syndrome. Ann Am Thorac Soc. 2017 May;14(5):706-13.

16 Johannesma PC, van de Beek I, van der Wel JW, Paul MA, Houweling AC, Jonker MA, et al. Risk of spontaneous pneumothorax due to air travel and diving in patients with BirtHogg-Dubé syndrome. Springerplus. 2016 Sep;5(1):1506.

17 Wood JR, Bellamy D, Child AH, Citron KM. Pulmonary disease in patients with Marfan syndrome. Thorax. 1984 Oct;39(10):780-4.

18 Oderich GS, Panneton JM, Bower TC, Lindor NM, Cherry KJ Jr, Noel AA, et al. The spectrum, management and clinical outcome of Ehlers-Danlos syndrome type IV: a 30-year experience. J Vasc Surg. 2005 Jul;42(1):98106.

19 Nakagawa H, Wada H, Hajiro T, Nagao T, Ogawa E, Hatamochi A, et al. Ehlers-Danlos syndrome type IV with bilateral pneumothorax. Intern Med. 2015;54(24):3181-4.

20 Vassallo R, Ryu JH, Schroeder DR, Decker PA, Limper AH. Clinical outcomes of pulmonary Langerhans'-cell histiocytosis in adults. N Engl J Med. 2002 Feb;346(7):48490.

21 Mendez JL, Nadrous HF, Vassallo R, Decker PA, Ryu JH. Pneumothorax in pulmonary Langerhans cell histiocytosis. Chest. 2004 Mar;125(3):1028-32.

22 Ryu JH, Moss J, Beck GJ, Lee JC, Brown KK, Chapman JT, et al.; NHLBI LAM Registry Group. The NHLBI lymphangioleiomyomatosis registry: characteristics of 230 patients at enrollment. Am J Respir Crit Care Med. 2006 Jan;173(1):105-11.

23 Almoosa KF, Ryu JH, Mendez J, Huggins JT, Young LR, Sullivan EJ, et al. Management of pneumothorax in lymphangioleiomyomatosis: effects on recurrence and lung transplantation complications. Chest. 2006 May; 129(5):1274-81.

24 Steagall WK, Glasgow CG, Hathaway OM, Avila NA, Taveira-Dasilva AM, Rabel A, et al. Genetic and morphologic determinants of pneumothorax in lymphangioleiomyomatosis. Am J Physiol Lung Cell Mol Physiol. 2007 Sep;293(3):L800-8.

25 Elborn JS. Cystic fibrosis. Lancet. 2016 Nov; 388(10059):2519-31.

26 Daccord C, Nicod LP, Lazor R. Cystic Lung Disease in Genetic Syndromes with Deficient Tumor Suppressor Gene Function. Respiration. 2017;94(6):467-85.

27 Tobino K, Hirai T, Johkoh T, Kurihara M, Fujimoto K, Tomiyama N, et al. Differentiation between Birt-Hogg-Dubé syndrome and lymphangioleiomyomatosis: quantitative analysis of pulmonary cysts on computed to- mography of the chest in 66 females. Eur J Radiol. 2012 Jun;81(6):1340-6.

28 Castellani C, Massie J, Sontag M, Southern KW. Newborn screening for cystic fibrosis. Lancet Respir Med. 2016 Aug;4(8):653-61.

29 Bernstein J, Robbins TO. Renal involvement in tuberous sclerosis. Ann N Y Acad Sci. 1991; 615:36-49.

30 Azim A, Rajkumar G. Renal angiomyolipomas in tuberous sclerosis-rare but potentially life-threatening lesions. BMJ Case Rep. 2012 Dec;2012 dec14 1:bcr2012007720.

31 Houweling AC, Gijezen LM, Jonker MA, van Doorn MB, Oldenburg RA, van SpaendonckZwarts KY, et al. Renal cancer and pneumothorax risk in Birt-Hogg-Dubé syndrome; an analysis of 115 FLCN mutation carriers from 35 BHD families. Br J Cancer. 2011 Dec; 105(12):1912-9.

32 Dal Sasso AA, Belém LC, Zanetti G, Souza CA, Escuissato DL, Irion KL, et al. Birt-HoggDubé syndrome. State-of-the-art review with emphasis on pulmonary involvement. Respir Med. 2015 Mar;109(3):289-96.

33 Klomp JA, Petillo D, Niemi NM, Dykema KJ, Chen J, Yang XJ, et al. Birt-Hogg-Dubé renal tumors are genetically distinct from other renal neoplasias and are associated with up-regulation of mitochondrial gene expression. BMC Med Genomics. 2010 Dec;3(1):59.

34 Adley BP, Smith ND, Nayar R, Yang XJ. BirtHogg-Dubé syndrome clinicopathologic findings and genetic alterations. Arch Pathol Lab Med. 2006;130:1865e70.

35 Choyke P, Glenn G, Walther M. Hereditary renal cancers. Radiology 2003;226:33-46.

36 Menko FH, van Steensel MA, Giraud S, FriisHansen L, Richard S, Ungari S, et al.; European BHD Consortium. Birt-Hogg-Dubé syndrome: diagnosis and management. Lancet Oncol. 2009 Dec;10(12):1199-206.

37 Byrne M, Mallipeddi R, Pichert G, Whittaker S. Birt-Hogg-Dubé syndrome with a renal angiomyolipoma: further evidence of relationship between Birt-Hogg-Dubé syndrome and tuberous sclerosis complex. Australas J Dermatol. 2012;53:151e4.

38 Toro JR, Glenn G, Duray P, Darling T, Weirich G, Zbar B, et al. Birt-Hogg-Dubé syndrome: a novel marker of kidney neoplasia. Arch Dermatol. 1999 Oct;135(10):1195-202.

39 Vishnevskiü AA, Nikoladze GD, Romanov IV. [Familial bullous disease of the lungs as a cause of spontaneous pneumothorax]. Grud Serdechnososudistaia Khir. 1990;2(6):44-6.

40 Koivisto PA, Mustonen A. Primary spontaneous pneumothorax in two siblings suggests autosomal recessive inheritance. Chest. 2001 May;119(5):1610-2.

41 Maffé A, Toschi B, Circo G, Giachino D, Giglio S, Rizzo A, et al. Constitutional FLCN mutations in patients with suspected BirtHogg-Dubé syndrome ascertained for noncutaneous manifestations. Clin Genet. 2011 Apr;79(4):345-54. 